như vắc xin sởi. Các trường hợp suy giảm HGKT sau tiêm so với trước tiêm do yếu tố thời gian, kèm theo sử dụng trong trung hòa vi rút của vắc xin và không tạo đáp ứng miễn dịch.Vắc xin MRVAC cho kêt quả khá tốt ở nhóm chưa có kháng thể trước tiêm với tỉ lệ chuyển đổi huyết thanh rất cao, cải thiện rõ rệt tỉ lệ có kháng thể sau tiêm, những chỉ số này tương đương với vắc xin đối chứng, tuy nhiên GMT sau tiêm thấp hơn nhiều chủng rubella ở các nghiên cứu khác. Tuy vắc xin MRVAC không tạo đáp ứng miễn dịch với nhóm có kháng thể kháng vi rút rubella trước tiêm như vắc xin đối chứng nhưng hiện tại thì sự cần thiết của liều tăng cường rubella cũng chưa được chứng minh, thời gian tồn lưu của kháng thể kháng vi rút rubella sau tiêm chủng rất dài bất chấp sự sự giảm của HGKT, tỉ lệ có kháng thể của quần thể luôn giữ rất cao qua hàng chục năm nên điều này không thật sự quan trọng [4],[5].

\section{KẾT LUẬN}

Vắc xin MRVAC đạt yêu cầu về tính sinh miễn dịch với vi rút rubella, cụ thể: ở nhóm chưa có miễn dịch với rubella trước tiêm vắc xin, tỉ lệ chuyển đối huyết thanh sau tiêm là $98,4 \%$ (96,9\%-100\%) đến 99,3\% (97,9\%-100\%), hiệu giá kháng thể trung bình nhân (GMT) kháng vi rút rubella sau tiêm MRVAC là 32,00 EIA unit, thấp hơn có ý nghĩa so với nhóm đối chứng. Ớ nhóm đã có kháng thể, GMT sau tiêm MRVAC là 49,87 EIA unit, tương đương so với trước tiêm và vắc xin đối chứng.

\section{TÀI LIỆU THAM KHẢO}

1. Susan E. Reef, Stanley A. Plotkin (2017), "Rubella Vaccines", Plotkin's Vaccines,7th edition, Elsevier, Philadelphia, USA: 970-1000.

2. Trân Như Dương, Vũ Hải Hà, Phạm Quãang Thái và cs (2016), "Một số đặc điểm dịch tễ hội chứng rubella bẩm sinh được giám sát tai Bênh viện Nhi Trung ương, 2011-2016", Tạp chí Y học dự phòng, 10(183): 35-42.

3. Takeuchi $Y$, Togashi $T$, Sunakawa $K$ et al (2002), "Field trial of combined measles and rubella live attenuated vaccine", Infectious disease magazine, 76(1), pp.56-62.

4. WHO (2008), The Immunological Basis for Immunization Series. Module 11: Rubella 2008.

5. Susan E. Reef, Stanley A. Plotkin (2017), "Rubella Vaccines", Plotkin's Vaccines,7th edition, Elsevier, Philadelphia, USA: 970-1000.

\title{
KẾT QUẢ ĐIỀU TRỊ CAN THIỆP NÚT PHÌNH ĐộNG MẠCH SỐNG - NỀN TẠI BỆNH VIỆN NHÂN DÂN 115
}

\section{TÓM TẮT}

Mục tiêu: Đánh giá kết quả điều trị can thiêp nút phình động mạch sống - nền trong điêu trị đột quy. chảy máu khoang dưới nhện do võ̃ phình động mạch sống - nền. Đối tượng và phương pháp: Nghiên cứu tiến cứu, mở, cắt ngang, không đối chứng có theo dõi dọc trên 51 bệnh nhân đột quy chảy máu điều trị nội trú tại bệnh viện Nhân dân 115, từ 1/2014 đến 12/2018. Kết quả: Có $80,39 \%$ túi phình được can thiệp gây tắc hoàn toàn và $13,72 \%$ túi phình được gây tắc bán phần và tái võ̃ phình sau can thiệp là 5,89\%. Đa số các bệnh nhân có điểm GOS là 5 lúc ra viện chiếm $72,56 \%$. Thang điểm Rankin sửa đổi khi ra viện, chủ yếu có Rankin 1 điểm chiếm 47,06\%. Kiểm tra GOS sau 3 tháng mức tốt chiếm 20,45\%; sau 6

\footnotetext{
${ }^{1}$ Trường Đại học Y khoa Phạm Ngọc Thạch ${ }^{2}$ Hoc viên Quần $Y$

Chịu trách nhiệm chính: Tống Đức Minh

Email: minhhoa142@gmail.com

Ngày nhận bài: 25/11/2020

Ngày phản biện khoa học: 10/12/2020

Ngày duyệt bài: 19/12/2020
}

Phùng Quốc Thái ${ }^{1}$, Phạm Ngọc Hoa ${ }^{1}$,
Bùi Quang Tuyển ${ }^{2}$, Tống Đức Minh ${ }^{2}$

tháng $(22,73 \%)$; sau 12 tháng điểm GOS mức tốt chiếm $65,91 \%$. Kết quả kiểm tra hình ảnh tỷ lệ tái thông sau ra viện 3 tháng chiếm 4,55\%; sau 6 tháng $(6,82 \%)$; sau 12 tháng, tái thông chiếm $18,18 \%$. Kết luận: Chủ yếu các túi phình được xử trí gây tắc hoàn toằn. Lúc ra viện, đa số bệnh nhân có GOS là 5 và Rankin sửa đổi là 1 điểm. Kết quả tái thông sau can thiệp động mạch dưới $20 \%$.

Tư khóa: Điều trị can thiệp nút động mạch, phình động mạch sống - nền.

\section{SUMMARY}

RESULTS OF INVASIVE TREATMENT TO CLOG ANEURYSMS OF VERTEBROBASILAR

\section{ARTERY AT PEOPLE'S HOSPITAL 115}

Objective: To evaluate the treatment results of intervention to clog aneurysms of vertebrobasilar artery in the treatment of subarachnoid haemorrgic stroke due to the bursted aneurysms of vertebrobasilar artery. Subjects and methods: A prospective, open, cross-section, non-controlled study with vertical follow-up of 51 haemorrgic stroke patients treated inpatient at People's Hospital 115, from $1 / 2014$ to $12 / 2018$. Results: $80.39 \%$ of the 
aneurysm was completely obstructed and $13.72 \%$ of the aneurysm was partially obstructed and the rupture of the aneurysm after intervention was $5.89 \%$. The majority of patients with GOS score of 5 at discharge accounted for $72.56 \%$. Revised Rankin scale at discharge, mainly Rankin 1 point accounted for $47.06 \%$. GOS inspection after 3 months of good level accounted for $20.45 \%$; after 6 months $(22.73 \%)$; after 12 months, good GOS score accounted for $65.91 \%$. Imaging examination results, the rate of recirculation after 3 months of discharge from hospital accounted for $4.55 \%$; after 6 months $(6.82 \%)$; after 12 months, it accounted for $18.18 \%$. Conclusion: The aneurysms was mainly treated with complete obstruction. At discharge, the majority of patients had a GOS of 5 and a revised Rankin of 1 point. Results of recirculation after artery intervention less than $20 \%$.

Key words: The invasive treatment to clog artery, Aneurysms of vertebrobasilar artery.

\section{I. ĐĂT VẤN ĐỀ}

Võ phình động mach nội sọ là nguyên nhân chính (85\%) gây xuất huyết khoang dưới nhện không do chân thương, gây "cơn đau đâu tệ nhất trong đời" [1], [2]. Xuất huyết khoang dưới nhện là nguyên nhân gây tàn phế và tử vong hàng đầu. Tỉ lệ tử vong trong 30 ngày lên gần $50 \%$, những người sống sót thì $25 \%$ tàn phế, số còn lại gia tăng nguy cơ đôtt quy, chảy máu lai hoắc có những biến chứng khác. Vỡ PĐMN có hai cách điều trị là phẫu thuật kẹp cổ túi phình và can thiệp nội mạch nút túi phình bằng vòng xoắn kim loại (VXKL) có hoặc không trợ giúp bóng hoặc giá đỡ nội mạch (thay đổi hướng dòng chảy) giúp bảo tồn mạch mang [3]. Điều trị can thiệp nội mạch là đặt vào lòng túi phình những vòng xoắn kim loại gây đông máu nút kín túi phình, loại túi phình khỏi hệ động mạch mà vẫn đảm bảo lưu thông của động mạch mang túi phình. Tuy nhiên, ở Việt Nam kỹ thuật này mới chỉ bắt đầu, chưa được tiển hành rộng rãi. Việc nghiên cứu lâm sàng, hình ảnh chụp động mạch, chỉ định điều trị bằng phương pháp can thiệp nội mạch, cũng như đánh giá kết quả sau điều trị là rất cân thiết, góp phần vào việc giúp người bệnh trở lại cuộc sống hằng ngày với chất lượng cao nhất có thể, hạn chế tối đa các di chứng thần kinh và tỷ lệ tử vong. Do đó, chúng tôi thực hiên nghiên cứu này, nhằm mục tiêu sau: "Đánh giá kêt quả điều trị can thiệp nút phinh động mạch sông - nền trong điều trị đột quy chày máu khoang dưới nhện do vỡ phinh động mạch sống - nền".

\section{II. ĐỐI TƯợNG VÀ PHƯƠNG PHÁP NGHIÊN CỨU}

2.1. Đối tượng nghiên cứu. Gồm 51 bệnh nhân đột quy chảy máu khoang dưới nhện do võ phình động mach Sống- Nền được xử trí nút phình mạch bằng phương pháp can thiệp nội mạch, điều trị nội trú tại bệnh viện Nhân dân 115 , từ 1/2014 đến 12/2018.

Tiêu chuẩn lựa chọn:

- Đau đầu đột ngột, cổ cứng, nôn, có thể: rối loạn ý thức, yếu vận động nửa người, liệt thần kinh so.

- Kết quả cắt lớp vi tính hoặc cộng hưởng từ não xác định có chảy máu khoang dưới nhện, não thất, chảy máu vào nhu mô não hoặc kết hợp.

- Tất cả bệnh nhân được chụp mạch não số hóa xóa nền xác định có phình động mạch não hệ động mạch Sống- Nền.

Tiêu chuẩn loại trừ:

- Bệnh nhân với các triệu chứng lâm sàng như trên không tìm thấy phình động mạch não sau khi chụp MNSHXN, bệnh nhân từ chối can thiệp.

- Các bệnh nhân có chống chỉ định can thiệp.

\subsection{Phương pháp nghiên cứu}

Thiết kế nghiên cứu: Nghiên cứu tiến cứu, mở, cắt ngang, không đối chứng có theo dõi dọc.

Chỉ định và chống chỉ định điêu trị can thiệp nội mạch

- Chỉ định điều tri. Tất cả các bênh nhân võ phình động mạch não tuổi 15 đến 82 có độ Hunt-Hess từ I đến III, độ WFNS từ I đến III được tiến hành can thiệp nội mạch ngay sau khi hoàn tất công tác chuẩn bị, các bệnh nhân có độ Hunt-Hess IV hoặc độ WFNS IV cần hồi sức tích cực nếu lâm sàng cải thiện tiến hành can thiệp, nếu không cải thiện hay nặng lên không can thiệp theo Pearse Morris, Wanke I.

- Chống chỉ định

+ Bệnh nhân có rối loạn đông cầm máu.

+ Chảy máu dưới nhệ̉n mức độ nặng Hunt Hess và WFNS độ V.

+ Bệnh nhân có bệnh nội khoa nặng kèm theo (suy thận, suy tim, suy gan).

+ Những bệnh nhân không thể tìm được đường vào động mạch đùi.

+ Dị ứng với thuốc cản quang và chống chỉ định với Heparin

+ Bệnh nhân tuổi cao trên 82.

+ Bệnh nhân chống chỉ định với gây mê nội khí quản.

Nội dung nghiên cứu:

- Phương pháp can thiệp: Kỹ thuật nút túi phình bằng vòng xoắn kim loại (VXKL), Nút phình mạch bằng keo, Giá đõ nội mạch (GĐNM), kỹ thuật đặt bóng kết hợp VXKL, kỹ thuật GĐNM kết hợp VXKL, kỹ thuât dùng keo và VXKL.

- Đánh giá kết quả điều trị qua chụp số hóa xóa nền ngay sau khi can thiệp.

+ Tỷ lệ thành công, tỷ lệ không nút đầy phình mạch. 
+ Tỷ lệ nút thành công phình mạch, tỷ lệ số bệnh nhân cần sử dụng các biện pháp hỗ trị đặt VXKL.

+ Chup CLVT ngay sau can thiêp để kiểm tra biến chứng võ̃ phình mạch trong khi nút VXKL để đánh giá tiên lượng, lập phương án điều trị tiếp theo.

- Đánh giá lâm sàng của bệnh nhân ra viện theo điểm Glasgow (GOS) và thang điểm Rakin sửa đổi.

- Khảo sát mối tương quan giữa kết quả ra viện theo điểm Glasgow (GOS) và mức độ lâm sàng khi vào viện (theo độ Hunt-Hess).

- So sánh kết quả theo thang điểm Glasgow (GOS) ở các thời điểm ra viện, sau 3 tháng, 6 tháng, 12 tháng.

- Theo dõi đánh giá kết quả hình ảnh sau nút phình mạch tại thời điểm 3 tháng, 6 tháng, 1 năm hoặc dài hơn nếu bênh nhân còn hợp tác bằng cộng hưởng từ mạch hoặc chụp động mạch số hóa xóa nền.

2.3. Phương pháp xử lý số liệu: số liệu thu thập được nhập và xử lý trên phần mềm thống kê y sinh học SPSS 22.0.

\section{KẾT QUẢ NGHIÊN CỨU}

Bảng 1. Phương pháp can thiêp nút phinh mạch

\begin{tabular}{|c|c|c|}
\hline $\begin{array}{c}\text { Phương pháp can } \\
\text { thiệp }\end{array}$ & $\begin{array}{c}\text { Số túi phình } \\
\text { (n=51) }\end{array}$ & $\begin{array}{c}\text { Tỉ lệ } \\
(\mathbf{\%})\end{array}$ \\
\hline $\begin{array}{c}\text { Nút phình mạch bằng } \\
\text { VXKL }\end{array}$ & 33 & 64,71 \\
\hline $\begin{array}{c}\text { Nút phình mạch bằng } \\
\text { keo }\end{array}$ & 5 & 9,80 \\
\hline Giá đỡ nội mạch (Stent) & 3 & 5,89 \\
\hline Bóng+ VXKL & 4 & 7,84 \\
\hline GĐNM+ VXKL & 2 & 3,92 \\
\hline Keo+ VXKL & 4 & 7,84 \\
\hline
\end{tabular}

Nhận xét: Các bệnh nhân được can thiệp chủ yếu bằng phương pháp nút phình mạch bằng VXKL với $64,71 \%$,sư dụng keo NCBA $9,80 \%$, VXKL có hố trơ phương pháp thứ hai phối hợp nút mạch như: Bóng 7,84\%, hoặc với GĐNM 3,92\% hoặc với keo NCBA 7,84\%. Với phình mạch cổ rất rộng dùng Stent chuyển dòng là $5,89 \%$.

Bảng 2. Điểm tiến triển Glasgow ở bệnh nhân khi ra viện

\begin{tabular}{|c|c|c|}
\hline GOS & Số bệnh nhân & Tỉ lệ (\%) \\
\hline 1 & 7 & 13,72 \\
\hline 2 & 0 & 0,0 \\
\hline 3 & 1 & 1,96 \\
\hline 4 & 6 & 11,76 \\
\hline 5 & 37 & 72,56 \\
\hline Tống số & $\mathbf{5 1}$ & $\mathbf{1 0 0}$ \\
\hline
\end{tabular}

Nhận xét: Trong tống số các bệnh nhân, đa số các bệnh nhân (37 bệnh nhân) có điểm GOS là 5 lúc ra viện chiếm $72,56 \%$, độ 4 là $11,76 \%$ và đô 1 có 7 bênh nhân với $13,72 \%$.

Bảng 3. Điểm Rankin sửa đổi ở bệnh nhân khi ra viện

\begin{tabular}{|c|c|c|}
\hline Rankin & Số bệnh nhân & Tỉ lệ \% \\
\hline 0 & 14 & 27,45 \\
\hline 1 & 24 & 47,06 \\
\hline 2 & 5 & 9,80 \\
\hline 3 & 1 & 1,96 \\
\hline 4 & 0 & 0,0 \\
\hline 5 & 7 & 13,73 \\
\hline 6 & 0 & 0,0 \\
\hline Tống & $\mathbf{5 1}$ & $\mathbf{1 0 0}$ \\
\hline
\end{tabular}

Nhân xét: Khi ra viện, 24 bênh nhân có Rankin 1 điểm chiếm 47,06\%, 14 bệnh nhân Rankin 0 điểm chiếm $27,45 \%$, Rankin 2 điểm chiếm 9,80\%, có 7 bệnh nhân Rankin 5 điểm chiếm 13,73\% và không có bệnh nhân Rankin 6 điểm.

Bảng 4. Kêt quả lâm sàng theo Hunt-Hess ( $n=51)$

\begin{tabular}{|c|c|c|c|c|c|c|c|c|}
\hline \multirow{3}{*}{ Hunt-Hess } & \multicolumn{6}{|c|}{ Điểm ra viên Glasgow } & \multirow{2}{*}{\multicolumn{2}{|c|}{ Tổng }} \\
\hline & \multicolumn{2}{|c|}{ V-IV (tốt) } & \multicolumn{2}{|c|}{ III-II (xấu) } & \multicolumn{2}{|c|}{ I (tử vong) } & & \\
\hline & $\mathbf{n}$ & $\%$ & $\mathbf{n}$ & $\%$ & $\mathbf{n}$ & $\%$ & $\mathbf{n}$ & $\%$ \\
\hline I - III & 40 & 90,91 & 1 & 2,27 & 3 & 6,82 & 44 & 100,0 \\
\hline IV - V & 3 & 42,86 & 0 & 0,0 & 4 & 57,14 & 7 & 100,0 \\
\hline Chung & 43 & 84,31 & 1 & 1,96 & 7 & 13,73 & 51 & 100,0 \\
\hline $\mathbf{p}$ & & & & & & & & \\
\hline
\end{tabular}

Hệ số tương quan Cramer's V = 0,504 (với $p=0,008$ ).

Nhận xét: Có mối liên quan giữa phân độ Hunt-Hess và GOS. Độ Hunt-Hess càng cao và độ GOS lúc ra viện càng thấp thì kết quả lâm sàng ra viện càng xấu

Bảng 5. Kết quả theo thang GOS sau ra viện 3, 6, 12tháng

\begin{tabular}{|c|c|c|c|c|c|c|c|c|}
\hline \multirow{3}{*}{ Thời gian } & \multicolumn{7}{|c|}{ Điểm tiến triến sau ra viện GOS } \\
\cline { 2 - 9 } & $\mathbf{5 - 4}$ (tốt) & $\mathbf{3 - 2}$ (xấu) & $\mathbf{1}$ (tữ vong) & Không kiếm tra \\
\cline { 2 - 9 } & $\mathbf{n}$ & $\mathbf{\%}$ & $\mathbf{n}$ & $\mathbf{\%}$ & $\mathbf{n}$ & $\mathbf{\%}$ & $\mathbf{n}$ & $\mathbf{\%}$ \\
\hline Ra viê̂n $(\mathrm{n}=51)$ & 43 & 84,31 & 1 & 1,96 & 7 & 13,73 & 0 & 0,0 \\
\hline 3 tháng $(\mathrm{n}=44)$ & 9 & 20,45 & 0 & 0,0 & 0 & 0,0 & 35 & 79,55 \\
\hline
\end{tabular}


VIETNAM MEDICAL JOURNAL N01 - JANUARY - 2021

\begin{tabular}{|c|c|c|c|c|c|c|c|c|}
\hline 6 tháng $(\mathrm{n}=44)$ & 10 & 22,73 & 0 & 0,0 & 0 & 0,0 & 34 & 77,27 \\
\hline 12 tháng $(\mathrm{n}=44)$ & 29 & 65,91 & 1 & 2,27 & 0 & 0,0 & 14 & 31,82 \\
\hline
\end{tabular}

Nhân xét: Số bệnh nhân tử vong sau khi ra viện là 7 bệnh nhân chiếm 13,73\%. Sau 3 tháng có 35 bệnh nhân không đi kiếm tra chiếm 79,55\%, có 9 người bệnh đi kiểm tra GOS mức tốt chiếm 20,45\%. Sau 6 tháng có 34 bệnh nhân không đi kiểm tra chiếm 77,27\%. Sau 12 tháng có 30 bệnh nhân kiểm tra với mức tốt là 29 bệnh nhân chiếm 65,91\%, mức xấu 1 bệnh nhân chiếm 2,27\%.

Bảng 6. Kết quả kiểm tra bằng chụp cộng hưởng từ có thuốc (MRA), chụp mạch số hóa xóa nền (MNXN) sau can thiêp

\begin{tabular}{|c|c|c|c|c|c|c|}
\hline \multirow{3}{*}{ Kết quả kiểm tra } & \multicolumn{6}{|c|}{ Thời gian (tháng) } \\
\hline & \multicolumn{2}{|c|}{3} & \multicolumn{2}{|c|}{6} & \multicolumn{2}{|c|}{12} \\
\hline & $\mathbf{n}$ & $\%$ & $\mathbf{n}$ & $\%$ & $\mathbf{n}$ & $\%$ \\
\hline Không tái thông & 7 & 15,91 & 7 & 15,91 & 22 & 50,0 \\
\hline Tái thông & 2 & 4,55 & 3 & 6,82 & 8 & 18,18 \\
\hline Số bệnh nhân bỏ kiếm tra & 35 & 79,55 & 34 & 77,27 & 14 & 31,82 \\
\hline Tống số & 44 & 100 & 44 & 100 & 44 & 100 \\
\hline
\end{tabular}

Nhận xét: Sau khi ra viện 3 tháng có 9 người bệnh tiến hành kiểm tra bằng chụp cộng hưởng từ có bơm thuốc, MNXN còn lai 36 người bênh đã bỏ kiểm tra. Kết quả có 2 bênh nhân tái thông chiếm 4,55\%. Sau 6 tháng có 10 bệnh nhân kiểm tra, trong đó có 3 bệnh nhân tái thông chiếm 6,82\%. Sau 12 tháng có 30 bệnh nhân tham gia kiểm tra, trong đó có 8 bệnh nhân tái thông chiếm tỉ lệ 18,18\%.

\section{BÀN LUÂN}

Các bệnh nhân được can thiệp chủ yễu bằng phương pháp nút phình mạch bằng VXKL với $64,71 \%$, sử dụng keo NCBA $9,80 \%$, VXKL có hỗ trợ phương pháp thứ hai phối hợp nút mạch như: Bóng 7,84\%, hoặc với GĐNM 3,92\% hoặc với keo NCBA 7,84\%. Với phình mạch cổ rất rộng dùng Stent chuyển dòng là $5,89 \%$. Tất cả các bệnh nhân đều có kết quả can thiệp đạt yêu cầu, trong đó có $80,39 \%$ túi phình được can thiệp gây tắc hoàn toàn và $13,72 \%$ tỷ lệ túi phình có kết quả gây tắc bán phần và tái võ̃ phình sau can thiệp là $5,89 \%$. So với một số các tác giả khác: Pierot $L$ và CS điều trị 236 bênh nhân với 138 bệnh nhân võ̃ phình mạch tỷ lệ nút kín hoàn toàn phình mạch $61,5 \%$, di sót tại cổ $33,2 \%$, nút bán phần 5,3\%[4].

Kết quả theo thang tiến triển Glasgow cho thây trong tổng số các bệnh nhân, đa số các bệnh nhân (37 bệnh nhân) có điểm GOS là 5 lúc ra viện chiếm $72,56 \%$, độ 4 là $11,76 \%$ và độ 1 có 7 bệnh nhân chiếm 13,72\%. Đối với thang điểm Rankin sửa đổi khi ra viện, 24 bệnh nhân có Rankin 1 điểm chiếm 47,06\%, 14 bệnh nhân Rankin 0 điểm chiếm $27,45 \%$, Rankin 2 điểm chiếm $9,80 \%$, có 7 bênh nhân Rankin 5 điểm chiếm $13,73 \%$ và không có bệnh nhân Rankin 6 điểm.

Về mối tương quan giữa thang điểm lâm sàng Hunt-Hess và kết quả ra viện theo thang Glasgow, có sự tương quan nghịch (với hệ số tương quan vừa - 0,504, $p=0,008$ ). Độ HuntHess càng thấp chỉ số ra viện theo thang tiến triển Glasgow càng cao và ngược lại.
Trong nghiên cứu của chúng tôi, có 7 bệnh nhân tử vong sau khi ra viện, chiếm 13,73\%. Sau 3 tháng có 9 BN đi kiểm tra GOS mức tốt chiếm 20,45\%. Sau 6 tháng có 10 bệnh nhân đi kiểm tra chiếm $22,73 \%$ có GOS ở mức tốt. Sau 12 tháng có 30 bệnh nhân kiểm tra với mức tốt là 29 bệnh nhân chiếm 65,91\%, mức xấu 1 bệnh nhân chiếm 2,27\%.Trong nghiên cứu quốc tế lớn nhất về võ̃ phình mạch ISAT được công bố năm 2002 được thực hiện ở Anh, Châu Âu, Hoa kỳ, Canada, Australia với 2.143 bệnh nhân võ phình mạch kết quả sau 12 tháng ở nhóm điều trị can thiệp nút mạch tỷ lệ tử vong và sống phụ thuốc là $23,7 \%$. Trong đó nhóm điều trị bằng phẩu thuật kẹp clip là 30,6\% [5]. Theo Nguyển Sơn, kết quả sau 22 tháng tốt là 87,4\% [6].

Việc theo dõi lâu dài sau can thiệp được tổ chức chặt chẽ theo lịch hẹn 3,6,12, với những phình mạch có nguy cơ tái thông cao đều được kiểm tra sớm sau hai đến ba tháng bằng chụp cộng hưởng từ mạch trên máy 1.5 Tesla của Philips với chế độ TOP-3D, nếu thấy phù hợp với chụp mạch số hóa xóa nền ngay sau khi can thiệp sẽ tiến hành chụp mạch số hóa xóa nền lại sau 6 tháng hoặc 12 tháng như các bệnh nhân khác. Sau khi ra viện 3 tháng có 2 bệnh nhân tái thông chiếm 4,55\%. Sau 6 tháng, bệnh nhân có tái thông chiếm $6,82 \%$. Sau 12 tháng, có 8 bệnh nhân tái thông chiếm tỉ lệ 18,18\%.Theo Nguyễn Minh Hiện và cs (2014), tái thông phình mạch sau can thiệp trong vòng 12 tháng là 7\% [7].

\section{KẾT LUÂ̂N}

Có 80,39\% túi phình được can thiệp gây tắc hoàn toàn và $13,72 \%$ tỷ lệ túi phình có kết quả 
gây tắc bán phân và tái võ phình sau can thiệp là $5,89 \%$.

Đa số các bênh nhân có điểm GOS là 5 lúc ra viện chiếm $72,56 \%$. Thang điểm Rankin sửa đổi khi ra viện, chủ yếu có Rankin 1 điểm chiếm $47,06 \%$.

Có 7 bệnh nhân tử vong sau khi ra viện, chiếm $13,73 \%$. Kiểm tra GOS sau 3 tháng mức tốt chiếm 20,45\%; sau 6 tháng (22,73\%). Sau 12 tháng điểm GOS mức tốt chiếm 65,91\%.

Kết quả kiểm tra hình ảnh tỷ lệ tái thông sau ra viện 3 tháng chiếm 4,55\%; sau 6 tháng $(6,82 \%)$; sau 12 tháng chiếm $18,18 \%$.

\section{TÀI LIÊU THAM KHẢO}

1. Fabrice Bonneville, Nader Sourour, Alessandra Biondi (2006). Intracranial aneurysms: an overview. Neuroimag Clin N Am, 16,: 371-382.

2. J. van Gijn, G. J. E. Rinkel (2001). Subarachnoid haemorrhage: diagnosis, causes and management. Brain, 124: 249-278.
3. Brad Seibert, Ramachandra P. Tummala, Ricky Chow, et al. (2011). Intracranial aneurysms: review of current treatment options and outcomes. Frontiers in Neurology 2.

4. L. Pierot, A. Bonafe, S. Bracard et al (2006). Endovascular treatment of intracranial aneurysms with matrix detachable coils: Immediate posttreatment results from a prospective multicenter registry. AJNR, 27: 1693-1699.

5. A. Molyneux, R. Kerr, R. Holman (2002). International Subarachnoid Aneurysm Trial (ISAT) of neurosurgical clipping versus endovascular coiling in 2143 patients with ruptured intracranial aneurysms: a randomised trial. The Lancet, 360: 1267-1274.

6. Nguyễn Sơn (2010). Nghiên cựu lâm sàng, chẩn đoán hình ảnh và điều trị vi phẩu thuât kep cổ túi phình động mạch não trên lều đã vỡ. Học viện Quân y.

7. Nguyển Minh Hiện, Phạm Đình Đài, Đỗ Đức Thuấn (2014). Nghiên cứu biểu hiện lâm sàng, hình ảnh và kết quả điều trị can thiêp nội mạch ph Inh động mạch não đã võ ở bệnh viện quân y 103. Tạp chí y dược học quân sự, 9: 138-144.

\title{
KẾT QUẢ PHẪU THUÂT NộI SOI KHỚP VAI TRONG ĐIỀU TRI TỔN THƯO'NG SLAP
}

\author{
Nguyễn Hà Ngọc ${ }^{1}$, Nguyễn Tiến Bình ${ }^{2}$, Tống Đức $\mathrm{Minh}^{2}$
}

\section{TÓM TẮT}

Mục tiêu: Đánh giá kết quả phẫu thuât nội soi khớp vai trong điều trị tổn thương SLAP tại Bệnh viện Quân Y 175. Đối tượng và phương pháp: Nghiển cứu tiến cứu mô tả can thiệp, không đối chứng trên 54 bênh nhân được chẩn đoán xác đinh tổn thương SLAP và được phẫu thuật nội soi khẩu sụn viền tại Bênh viên Quân $Y 175$, thành phố Hồ Chí Minh từ 1/2014 đến 12/2018. Kết quả: Biên độ vận động khớp vai bên tổn thương, sau mổ 12 tháng có sự cải thiện có ý nghĩa về các động tác dạng vai, xoay ngoài và xoay trong so với 6 tháng sau phẫu thuật. Tổng điểm UCLA trung bình sau mố 6 tháng là $27,78 \pm 1,61$ và sau 12 tháng là $32,13 \pm 1,37$. Sau 6 tháng phẫu thuật điểm VAS trung bình là $1,50 \pm 0,50$ và sau 12 tháng phẫu thuật điểm trung bình là $0,54 \pm 0,50$. Sự khác biệt là có ý nghĩa thống kê với $p<0,001$. Có 34 trường hợp có thể quay lại thực hiên các môn thể dục thể thao (TDTT) như trước khi phấu thuât, chiếm tỷ lệ 62,96\%. Biến chứng trong mổ: 2/54 bệnh nhân bị vỡ đường hầm xương ổ chảo khi đặt vít neo. Kết luận: Sau 12 tháng, biên độ phục hồi vận động khớp vai cải thiện gân hoàn toàn. Tổng điểm UCLA cải thiện đáng

${ }^{1}$ Bệnh viện Quân y 175

${ }^{2}$ Hoc viên Quân y

Chịu trách nhiệm chính: Tống Đức Minh

Email: minhhoa142@gmail.com

Ngày nhận bài: 25/11/2020

Ngày phản biện khoa hoc: 11/12/2020

Ngày duyệt bài: 19/12/2020 kể. Điểm VAS giảm nhiều, gần như không còn đau sau 12 tháng phẫu thuật. Tỷ lệ quay lại vận động, thực hiện các môn TDTT chiếm tỷ lệ cao.

Tư khóa: Phẫu thuật nội soi, khớp vai, tổn thương slap.

\section{SUMMARY}

RESULTS OF LAPAROSCOPIC SURGERY IN THE SHOULDER JOINT IN THE TREATMENT OF SLAP LESIONS

Objective: Evaluating the results of laparoscopic surgery in the shoulder joint in the treatment of SLAP lesions at 175 Military Hospital. Subjects and methods: A study of descriptive-intervention, no control on 55 patients definitely diagnosed SLAP lesions and endoscopic surgery to stitch cartilage at 175 Military Hospital, Ho Chi Minh City from January, 2014 to September, 2018. Results: Amplitude of movement in the injured side shoulder joint, 12 months after surgery, there was a significant improvement in shoulder abduction, outer rotation and inner rotation compared to 6 months after surgery. The average total UCLA score after 6 months of surgery was $27.78 \pm 1.61$ and after 12 months was $32.13 \pm 1.37$. After 6 months of surgery, the average VAS score was $1.50 \pm 0.50$ and after 12 months of surgery the average score was $0.54 \pm 0.50$. The difference was statistically significant with $p<0.001$. There were 34 cases that can return to perform sports (physical training) as before surgery, accounting for $62.96 \%$. Complications in surgery: 2/54 patients broken the tunnel of the Glenoid cavity of the 